\title{
Letter detection: A window to unitization and other cognitive processes in reading text
}

\author{
ALICE F. HEALY \\ University of Colorado, Boulder, Colorado
}

\begin{abstract}
Experiments are reviewed that use the letter-detection task, in which subjects read text and circle target letters. Evidence is provided that the letter-detection task reveals the processing units used in reading text and is influenced as well by visual, phonetic, and a combination of semantic and syntactic factors. Specifically, it is shown that circling a target letter in a word depends on the familiarity of the word's visual configuration, the location of the word in the reader's visual field, the phonetic representation of the letter in the word, and a combination of the word's meaning and its grammatical function.
\end{abstract}

For the past two decades my colleagues and I have been using a very simple letter-detection task to study the cognitive processes involved in reading text. Our earlier work with this task illuminated the basic processing units used in reading text (see Healy, 1981a, for a summary). Our more recent research with the same task, although continuing to support the importance of processing units, has examined a broader spectrum of cognitive processes and has consequently thrown light on visual, phonetic, and a combination of semantic and syntactic factors that influence letter- and word-identification processes in reading. In this article, I begin by reviewing some of the earlier work on unitization and then review some of the more recent studies highlighting the importance of other cognitive processes.

\section{Unitization}

The basic letter-detection task we have been using is illustrated in Table 1 with a 100-word passage from Golding (1959). One striking finding from this task is that subjects make an extremely large number of errors on the word the. Drewnowski and Healy (1977) proposed a set of hypotheses, referred to as the unitization hypotheses, to account for this "missing-letter" effect. According to these hypotheses, we can use featural information to identify supraletter units, such as syllables, words, or even short phrases, without necessarily having to complete

Preparation of this article was supported in part by Army Research Institute Contract MDA903-93-K-0010 to the University of Colorado. I am grateful to Bob Crowder, Betty Ann Levy, an anonymous reviewer, and especially Jim Neely for very helpful and thoughtful comments concerning earlier versions of this article, which is based on an invited presentation at the 1991 meeting of the American Psychological Association, never delivered due to my sustaining a ruptured appendix. I would like to take this opportunity to express my deepest gratitude to my surgeon, Dr. John Day, for saving my life at that time. Correspondence should be sent to the author at the Department of Psychology, Muenzinger Building, University of Colorado, Campus Box 345, Boulder, CO 80309-0345 (e-mail: ahealy@clipr.colorado.edu). letter identification. The identification of these higherorder units is facilitated by familiarity; for example, common words are identified as units more easily than rare words. It is also proposed that once a larger unit is identified, the processing of its component letter units is terminated, even if the letters have not yet reached the point of identification. Instead, processing and attention are directed to the next location in the text. Because letter identification is not always completed for highly familiar words such as the, many letter-detection errors are made on those words.

It has been argued that the letter-detection task distorts the normal processes used in reading (see, e.g., Rayner \& Pollatsek, 1989). Following from the observation that letter detection poses an additional requirement (circling target letters) superimposed on the normal reading task, this argument is that such a requirement may alter the processing units employed by the readers. However, it has been demonstrated under different circumstances that it is difficult for subjects to disengage their normal reading responses even when a laboratory task demands that they do so (see, e.g., MacLeod, 1991; Stroop, 1935). Further, it has been shown that the missingletter effect is, if anything, increased when subjects are given explicit instructions to comprehend the material they are reading (e.g., Proctor \& Healy, 1985; Smith \& Groat, 1979) and that the missing-letter effect is decreased or reversed when subjects are prevented from using their normal left-to-right reading pattern (e.g., Drewnowski \& Healy, 1977; Hadley \& Healy, 1991; Healy, Oliver, \& McNamara, 1987).

Initial experiments. In an initial series of experiments (Healy, 1976), I tried to distinguish between the unitization hypotheses and three reasonable alternative explanations for the missing-letter effect, which I have termed the location, pronunciation, and redundancy hypotheses. According to the location hypothesis, subjects miss the $t$ in the because of its location at the start of a three-letter word. The pronunciation hypothesis accounts 
Table 1

Instructions and Sample Passage for Letter Detection Task

\section{Instructions}

Your task is to read the passage below at your normal reading speed, but whenever you come to a letter $t$, encircle it with your pen or pencil. If at any time you realize that you missed a $t$ in a previous word, do not retrace your steps to encircle the $t$. You are not expected to get every $t$, so do not slow down your reading speed in order to be overcautious about getting the $t \mathrm{~s}$.

\section{Passage}

Smoke was rising here and there among the creepers that festooned the dead or dying trees. As they watched, a flash of fire appeared at the root of one wisp, and then the smoke thickened. Small flames stirred at the bole of a tree and crawled away through leaves and brushwood, dividing and increasing. One patch touched a tree trunk and scrambled up like a squirrel. The smoke increased, sifted, rolled outwards. The squirrel leapt on the wings of the wind and clung to another standing tree, eating downwards. The fire laid hold on the forest and began to gnaw. [Golding, 1959 (pp. 56-57)]

for the large number of errors on the in terms of the somewhat atypical pronunciation of the $t$ : Perhaps subjects searching for $t$ s scan a phonetic representation of the passage, formed by phonological recoding; if so, it would be reasonable to expect them to miss $t \mathrm{~s}$ that are not pronounced in the usual fashion. This hypothesis is consistent with the results of a classic experiment reported by Corcoran (1966), who found that subjects searching for the letter $e$ in a magazine article missed more silent $e$ s (such as the $e$ in take) than pronounced $e$ s (such as the es in elephant). The third alternative explanation for the missing-letter effect-the redundancy hypothesis - was first proposed by Corcoran (1966), and refers to the semantic and syntactic redundancy, or predictability, of the word the in normal prose. Specifically, Corcoran, who had found that subjects were more likely to miss the $e$ in the than they were even to miss silent $e$, suggested that the word the may be "'taken for granted' and thus not scanned" (p. 658). With normal prose text, a reader should be able to anticipate when the word the would occur on the basis of the surrounding word context, and thus might skip over that word in order to pay more attention to words that provide more information.

In Experiment 1 (Healy, 1976), the location hypothesis was tested by comparing subjects' performance on two passages. For each passage, subjects were given instructions comparable to those in Table 1 and an identical prose passage. The scrambled-letter passage differed in one important respect: The letters did not form words, but instead were in a scrambled order. In particular, while the $t \mathrm{~s}$, punctuation marks, and interword spaces in this passage were the same as those in the prose passage, the location of the other letters was decided randomly. The first words from these passages are included in Table 2.

If the location of the letter $t$ were critical, subjects should make a disproportionately large number of errors on the $t$ s that occur in the word the in the prose passage and on those in the corresponding locations ("the locations") in the scrambled-letter passage. The results are summarized in Table 3 . The overall proportion of errors on the prose passage was greater than that on the scrambledletter passage, but the reading time was shorter on prose than it was on scrambled letters. Hence, there is a speedaccuracy trade-off in this task. ${ }^{1}$ For that reason it is not wise to compare the absolute proportions of errors made on $t \mathrm{~s}$ in the locations in the two passages, although those proportions are given in Table 3 . However, the conditional proportion of errors in the locations given that an error was made should not be influenced by any speedaccuracy trade-off. This measure is also shown in Table 3. The mean conditional proportion of errors expected on the basis of chance alone is .275 , because there were 40 $t$ s altogether and 11 of them occurred in the locations. Although the conditional proportion of errors in the prose passage was much greater than chance, in the scrambled-letter passage it was below the chance level, contrary to the location hypothesis prediction.

In Experiment 2 (Healy, 1976), Corcoran's (1966) redundancy hypothesis was tested. To do so, I constructed a scrambled-word passage, which was the same as the prose passage except for the arrangement of the words.

Table 2

Sample Text from Various Experiments

\footnotetext{
1. Healy, 1976:

Experiment 1

Prose: Smoke was rising here and there among the

Scrambled Letters: Irwsa eek dmenna ross igh tmaen esarr thp

Experiment 2

Scrambled Words: Rising tree root watched wings laid of the

Experiment 3

Thy: Rising tree root watched wings laid of thy

Experiment 4

Frequency: Valley history ocean kine mirage gender truce

2. Healy \& Drewnowski, 1983 :

Even flowers in the park withered and became leatehry

3. Healy, Oliver, \& McNamara, 1987:

She flicked her hrist and drew her hand from Doctof Harry's

4. Hadley \& Healy, 1991 :

5-letter window: / the /

15-letter window: /then the smoke/

5. Schneider, Healy, \& Gesi, 1991 :

Experiment 1

Normal: Finished files are the result of years of scientific study combined with the experience of years.

Asterisk: ${ }^{*} \mathrm{~F}^{*} \mathrm{i}^{*} \mathrm{n}^{*} \mathrm{i}^{*} \mathrm{~s}^{*} \mathrm{~h}^{*} \mathrm{e}^{*} \mathrm{~d}^{*}{ }^{*} \mathrm{f}^{*} \mathrm{i}^{*} \mathrm{l}^{*} \mathrm{e}^{*} \mathrm{~s}^{*}{ }^{*} \mathrm{a}^{*} \mathrm{r}^{*} \mathrm{e}^{*}{ }^{*} \mathrm{t}^{*} \mathrm{~h}^{*} \mathrm{e}^{*}$

${ }^{*} \mathrm{r}^{*} \mathrm{e}^{*} \mathrm{~s}^{*} \mathrm{u}^{*} \mathrm{l}^{*} \mathrm{t}^{*} \mathrm{o}^{*} \mathrm{f}^{*} \mathrm{y}^{*} \mathrm{e}^{*} \mathrm{a}^{*} \mathrm{r}^{*} \mathrm{~s}^{* *} \mathrm{o}^{*} \mathrm{f}^{*} \mathrm{~s}^{*} \mathrm{c}^{*} \mathrm{i}^{*} \mathrm{e}^{*} \mathrm{n}^{*} \mathrm{t}^{*} \mathrm{i}^{*} \mathrm{f}^{*} \mathrm{i}^{*} \mathrm{c}^{*}$

${ }^{*} \mathrm{~s}^{*} \mathrm{t}^{*} \mathrm{u}^{*} \mathrm{~d}^{*} \mathrm{y}^{*}{ }^{*} \mathrm{c}^{*} \mathrm{o}^{*} \mathrm{~m} \mathrm{~m}^{*} \mathrm{~b}^{*} \mathrm{i}^{*} \mathrm{~h}^{*} \mathrm{e}^{*} \mathrm{~d}^{* *} \mathrm{w}^{*} \mathrm{i}^{*} \mathrm{t}^{*} \mathrm{~h}^{*}{ }^{*} \mathrm{t}^{*} \mathrm{~h}^{*} \mathrm{e}^{*}$

${ }^{*} \mathrm{e}^{*} \mathrm{x}^{*} \mathrm{p}^{*} \mathrm{e}^{*} \mathrm{r}^{*} \mathrm{i}^{*} \mathrm{e}^{*} \mathrm{n}^{*} \mathrm{c}^{*} \mathrm{e}^{* *} \mathrm{o}^{*} \mathrm{f}^{*} \mathrm{y}^{*} \mathrm{e}^{*} \mathrm{a}^{*} \mathrm{r}^{*} \mathrm{~s}^{*}$. $^{*}$

6. Moravcsik \& Healy, in press:

Experiment 1

the: Even though it was a Thai dish, all of the ingredients were familiar except two: what were the and thong?

thy: Even though it was a Thai dish, all of the ingredients were familiar except two: what were thy and thong?

7. Moravcsik \& Healy, in press:

Experiment 2

the definite article: Claiming that the definite article has no meaning and hence is unnecessary, newspapers often omit it in order to be concise.

the: Claiming that the has no meaning and hence is unnecessary, newspapers often omit it in order to be concise.
} 
Table 3

Performance on Prose, Scrambled Letters, and Scrambled Words in Study by Healy (1976)

\begin{tabular}{lccc}
\hline \multicolumn{1}{c}{$\begin{array}{c}\text { Performance } \\
\text { Measure }\end{array}$} & Prose & $\begin{array}{c}\text { Scrambled } \\
\text { Letters }\end{array}$ & $\begin{array}{c}\text { Scrambled } \\
\text { Words }\end{array}$ \\
\cline { 2 - 4 }$\quad$ & & & \\
Reading time & (in seconds) & 55 & 53 \\
$p$ (error) & 47 & .04 & .13 \\
$p$ (error in the location) & .17 & .01 & .29 \\
$p$ (error in the location $/$ error) & .62 & .05 & .67 \\
\hline
\end{tabular}

The same words were employed, and the punctuation marks and instances of the word the were kept in the same locations, but the locations of the other words were scrambled at random, so that the passage no longer made sense. Hence, in the scrambled-word passage, the word the was not predictable on the basis of the surrounding word context. The first words are included in Table 2. According to the redundancy hypothesis, the conditional proportion of errors on the word the should be greatly reduced in the scrambled-word passage because that word would not be redundant or predictable. The results are summarized in Table 3. The mean conditional proportion of errors was no less in the scrambled-word passage than it was in the prose passage, contrary to the redundancy hypothesis prediction.

The pronunciation hypothesis was tested in Experiment 3 (Healy, 1976), in which a new scrambled-word passage was constructed which was identical to the one used in Experiment 2 except that every instance of the word the was replaced by the word thy. Thy was chosen because it is the same length as the, has the letter $t$ in the same location, and, most critically, has the letter $t$ pronounced in the same manner. The first words from this passage are included in Table 2 . In this experiment, subjects read both scrambled-word passages - the one with the and the one with thy-in a counterbalanced order. According to the pronunciation hypothesis, subjects should make many errors on thy as well as on the. Contrary to this prediction, the mean conditional proportion of errors was much lower for thy (.08) than it was for the (.52).

Experiment 4 (Healy, 1976) was aimed at testing the unitization hypotheses, according to which it is the high frequency of the word the which is critical, because the ability to process words in units larger than individual letters should be greatest for the most familiar words. I constructed a new scrambled-word passage which included only nouns, each of which occurred only one time. The words were selected with the constraint that every common word was paired with a rare word of the same length. Wherever a $t$, if any, occurred in the common word, a $t$ occurred in the same location of the corresponding rare word; for example, the common word fact was matched with the rare word pact. The first few words from this passage are included in Table 2 . In accordance with the unitization hypotheses, subjects made a significantly higher proportion of errors on common words $(.21)$ than they did on rare words (.16). Although the effect of frequency is not great, it is consistent with the large proportion of errors on the in the other experiments, because the is the most frequent word in English and is considerably more frequent than the nouns used as common words in this experiment.

This initial study (Healy, 1976) thus provided evidence in favor of the unitization hypotheses and against the alternative location, pronunciation, and semantic and syntactic redundancy hypotheses. It also ruled out an additional alternative explanation of the high error rate on the word the in terms of its within-text repetition (see, e.g., Kanwisher, 1987) since, although the word the was repeated frequently throughout the passage in Experiment 3, the word thy was repeated the same number of times but still yielded a low error rate. Likewise, each word occurred only once in Experiment 4, but there were still significantly more errors on common words than there were on rare words. This within-text-repetition explanation is also inconsistent with the results from Experiments 1 and 2 of the study by Moravcsik and Healy (in press), which will be discussed later.

Although, as reviewed below, subsequent research by myself and my colleagues has provided additional support for unitization and has continued to refute the specific alternative hypotheses considered in this first investigation (see, e.g., Healy, 1980; Healy \& Drewnowski, 1983; Proctor \& Healy, 1985), our most recent research has demonstrated the influence of other specific location factors, pronunciation factors, and a combination of semantic and syntactic factors in letter detection.

Other support for unitization. Whereas my first study (Healy, 1976) provided support for the importance of word frequency in determining the missingletter effect, subsequent studies provided more direct evidence for the unitization hypotheses. According to these hypotheses, subjects should make a large proportion of detection errors on familiar words such as the only when they can use featural information to identify familiar supraletter units. If the relevant featural information is disturbed so that it does not conform to the familiar higher-order unit, letter-detection errors should diminish. In a set of experiments by Healy and Drewnowski (1983), misspellings and other forms of alteration were used to disturb featural information. Only Experiment 1 will be reviewed here.

In this experiment, we introduced misspellings into a prose passage by transposing the order of the two letters immediately following the target letter. This manipulation alters the visual features of the words containing the target letter while preserving the word context and the features of the target itself. We constructed two versions of a prose passage. The passage contained instances of the word the as well as other test words, such as withered and leathery, which included the letter string the. In each version of the passage, half of the test words were misspelled. All misspellings were created by transposing the $h$ and $e$ following a $t$. Every test word was correctly spelled in one version and misspelled in the 
other. A short segment from one version is included in Table 2.

We found that subjects made many more errors on the word the than they did on the other test words and that they made more errors on correctly spelled words than they did on misspelled words. In addition, there was a significant interaction between these two factors, reflecting the fact that the large difference in error proportions between correctly spelled versions of the and other words (.49 and .08 , respectively) was eliminated when they were misspelled (the, .01 ; other words, .01 ). These results are in line with the unitization hypotheses, because supraletter units should be identified most easily for the most common word, the, not so easily for other correctly spelled words, and hardly at all for all misspelled words.

This experiment vividly illustrates the importance of familiarity in determining letter-detection errors. More errors are made both when the target letters are embedded within frequent words and when the words are spelled in their usual manner. Although these effects of familiarity are robust and easily interpreted, they are puzzling insofar as it is generally believed that familiarity aids, rather than hinders, perceptual processes. There are two lines of evidence that support the facilitating effects of familiarity in the perception of printed text, both of which come primarily from studies employing a tachistoscopic masking paradigm. The first, the so-called "word superiority effect," concerns the superior perception of letters that occur in words relative to nonword letter strings, and was investigated intensively following the demonstrations by Reicher (1969) and Wheeler (1970) that controlled for guessing biases. The second line of evidence, the "word-frequency advantage," concerns the superior perception of words that are frequent in the language relative to those that are less frequent. ${ }^{2}$ In contrast to these studies with the masking paradigm demonstrating that letter identification is aided by familiar word contexts, our letter-detection task has yielded strong results in the opposite direction. As I have already described, our studies with this task have demonstrated a large proportion of letter-detection errors in correctly spelled words relative to misspelled words (which we have termed the "word-inferiority effect"), as well as in frequent words relative to less frequent words (which we have called the "word-frequency disadvantage"). ${ }^{3}$

Although there are many procedural differences between the studies showing facilitating effects of familiarity and our studies showing disruptive effects, one factor seems to be crucial-namely, the number of words in view at any given time. In the studies demonstrating the word-superiority effect and the word-frequency advantage, the usual procedures include tachistoscopic presentation followed by masking of a single word or letter string at a time (but see, e.g., Krueger, 1970, 1982, and Krueger \& Weiss, 1976, for word-superiority effects with multi-item displays). The subject is typically required to make a response to each letter string, by deciding, for example, which one of two alternative letters occurred. In contrast, subjects in our letter-detection task read a continuous typewritten text and circle each instance of a target letter. Hence, at least several words are simultaneously in sight in this letter-detection task.

A number of theoretical accounts have been proposed for the word-superiority effect and the related wordfrequency advantage. The most influential has been the interactive-activation model proposed by McClelland and Rumelhart (1981; Rumelhart \& McClelland, 1982). According to this model, processing occurs in parallel at the levels of visual features, letters, and words, and activation at one level leads to excitation or inhibition at other levels. The important assumption providing for word superiority is the presence of excitatory feedback from word units to their component letter units. Whereas this model can thereby account for the facilitating effects of familiar contexts on letter identification, it has no straightforward way in which to account for disruptive effects.

Unitization hypotheses. In contrast, the unitization hypotheses discussed earlier provide a framework in which both the facilitating and the disruptive effects of familiarity can be understood. The operation of these hypotheses for the reading of a short segment of text by a hypothetical subject is illustrated in Figure 1. The actual input given to the subject is shown at the bottom of Figure 1 , and all the reading units identified by the subject are enclosed in boxes which are placed at different levels as a function of their size. The particular units identified depend on their familiarity to the subject as well as on factors specific to the given reading situation. Units can be identified either on the basis of visual features or as the result of the identification of component lower-level units, as indicated in Figure 1 by the solid arrows. The important assumption of the unitization hypotheses, which differentiates them from the interactiveactivation model, is that once a unit has been identified, the processing of its component lower-level units is terminated, even if they have not yet reached the point of identification; instead, processing and attention are driven to the next location in the text, as indicated in Figure 1 by the dashed arrows. Thus, in the example, the subject identifies the common word pair of the as a unit at the supraword level before having identified all of its component letters or words. In this case, the subject terminates the processing of the lower-level units in that segment of text and moves on to process the next segment, reading unit. If this subject were engaged in a letterdetection task with $t$ as target, an error would be made in this case because the letter $t$ would not be identified. Thus, according to these hypotheses, letter-detection errors should occur whenever a larger unit (such as of the) is identified prior to the identification of a target letter contained in that unit (such as $t$ ). Because familiarity with a unit is likely to aid its processing, letter-detection errors should occur most often when the higher-level units are familiar. In this way, the unitization hypotheses can account for the disruptive effects of familiarity on letter detection. ${ }^{4}$ 


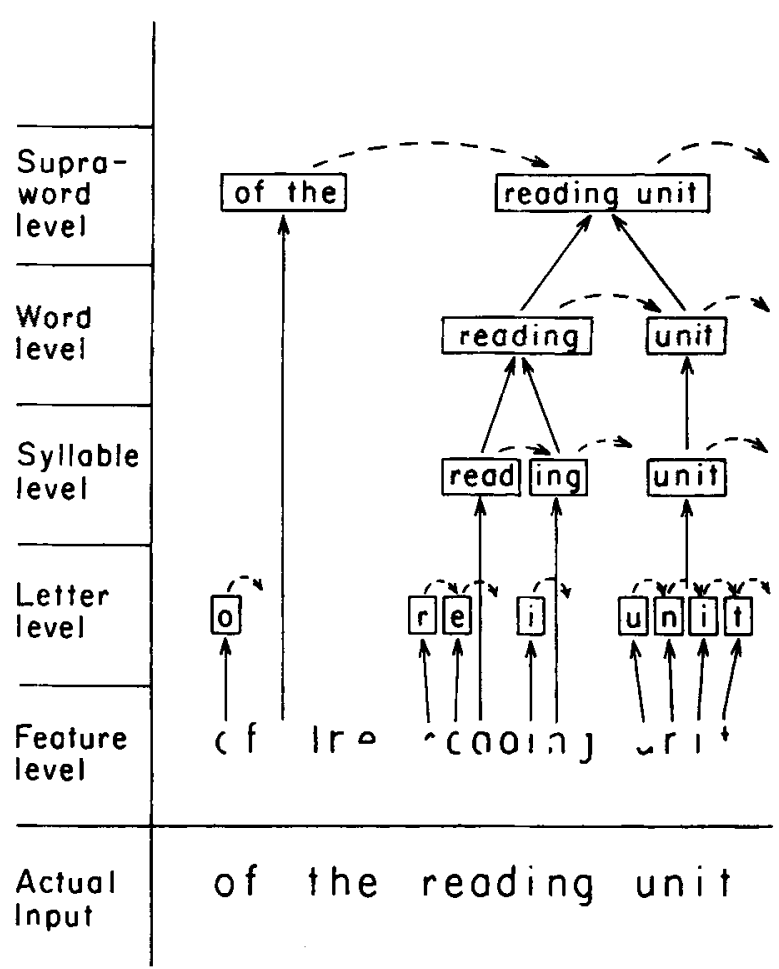

Figure 1. The operation of the unitization hypotheses for the reading of a short segment of text by a hypothetical subject.

Evidence for the assumptions embodied in Figure 1 comes from several sources. For instance, the need for four levels of reading units beyond the feature level (i.e., the letter level, the syllable level, the word level, and the supraword level) has been empirically documented. Data from Healy (1981b), Healy, Volbrecht, and Nye (1983), and Schneider and Healy (1993) provide evidence concerning the nature and processing of the letter level; these studies showed, for example, that subjects tolerate missing letter features but do not tolerate additional features. Drewnowski and Healy (1980) reported data relevant to the syllable level; this study showed that the suffix morpheme -ing serves as a single unit in reading. Healy and Cunningham (1992) and Schneider and Healy (1993) investigated unitization at the word level; for example, it was shown that word shape is an important variable in recognizing familiar words. Finally, Drewnowski and Healy (1977), Healy, Conboy, and Drewnowski (1987), and Healy and Drewnowski (1983) reported evidence concerning the supraword level; in these studies it was shown, for example, that the reading unit for the includes the preceding interword space.

The claim that the particular units identified depend on their familiarity for the subject is supported by studies investigating changes in familiarity due to development in children (Cunningham, Healy, Kanengiser, Chizzick, \& Willitts, 1988; Drewnowski, 1978, 1981). These studies provided evidence for the use of increasingly larger units as the subjects' reading ability increases. Healy, Fendrich, and Proctor (1990) and Proctor and
Healy (in press) investigated changes in familiarity due to training and demonstrated a substantial decline in the magnitude of the word-frequency disadvantage with practice. It was also shown that this decline was highly specific to the particular target letters and test words used during training but could not be attributed simply to a change in the subjects' conscious detection strategy, such as a realization on the part of the subjects that a particular word (like the) always contains a target letter. For example, in one study (Proctor, Healy, \& Fendrich, 1988) subjects were given instructions explicitly telling them that the word the contains the target and that they should be careful not to forget to mark it. These instructions did lead to an increase in the number of targets detected in the word the, thus reducing the magnitude of the word-frequency disadvantage, but a substantial effect remained.

How can the unitization hypotheses accommodate the facilitating effects of word context on letter identification found in tachistoscopic masking procedures? It is assumed that subjects move on to the next word in the text once they have identified a given word. However, if there is no subsequent word to which the subjects can direct their attention, as when only one word is in view, the subjects would naturally continue to process the single word in view once it has been identified. Under those circumstances, processing at the letter level may be facilitated rather than disrupted by word identification because of inferences based on the word's identity, such as the inference that a $t$ must be present because the word the was identified. Thus, the unitization account can explain both the disruptive effects of familiarity with the letter-detection paradigm and the facilitating effects of familiarity with tachistoscopic masking procedures. It does so by assuming that the faster processing of familiar words leads subjects to spend less time processing component letters in the letter-detection paradigm but affords them more time to process component letters in the tachistoscopic masking procedures.

Effects of display size. These hypotheses lead to the prediction that a familiar word context will disrupt letter detection when several words are simultaneously in view but will enhance letter detection when only one word is in view at a time. Healy, Oliver, and McNamara (1987) tested this prediction by employing a new letterdetection task in which the number of words in view was systematically manipulated. This procedure, which is a variant of the rapid serial visual presentation technique developed by Forster (1970), involves the presentation of continuous text on a computer display screen. Each display is shown for a fixed amount of time at the same location, and the subjects are to press a response key whenever they detect the target. In reviewing this 1987 study here, I will describe only Experiment 1 , in which we examined the effect of word frequency by comparing the, the most frequent word in English, with other, less frequent words and assessed the existence of wordsuperiority or word-inferiority effects by comparing correctly spelled words with words that were misspelled 
by replacing one of the correct letters with another letter. The text read by subjects was a prose passage, a short segment of which is included in Table 2. The following three conditions were compared: (1) the "paper" condition, in which subjects read the text and circled each instance of the letter $t$, as in the standard letter-detection task; (2) the "four-word" condition, in which the text was presented on a computer display screen four words at a time for a fixed duration and the subjects pressed a response key whenever they detected the target letter (the passage was written so that there was a maximum of one target in every four-word display); and (3) the "oneword" condition, which was just like the four-word condition except that only one word was displayed at a time.

The results are summarized in Table 4 in terms of mean error proportions as a function of condition, testword type, and test-word spelling. As in the earlier studies, subjects in the paper condition made more errors on correctly spelled words than they did on misspelled words, and they made more errors on the very common word the than they did on other, less frequent words. More importantly, there was a large interaction between test-word type and test-word spelling, reflecting the fact that the difference between the and other words was greatly reduced when the words were misspelled. The pattern of errors for the four-word condition was similar to that in the paper condition, although somewhat less striking. But the pattern of errors in the one-word condition was very different: There was no difference in this case between correctly spelled words and misspelled words, and subjects made significantly fewer errors on the than they did on other, less frequent words. ${ }^{5}$ These results reflect a strong word-inferiority effect and a strong word-frequency disadvantage for the four-word and paper conditions, in contrast to the absence or reversal of these effects for the one-word condition. These findings are consistent with the unitization hypotheses, which imply that the number of words in view at a given time is crucial because subjects can only move on to the next word in the text-leading to disruptive effects of word familiarity - if more than one word is in view. ${ }^{6}$

\section{Visual Factors}

Healy, Oliver, and McNamara (1987) explained the findings for the one-word condition by suggesting that with only one word in view subjects may be led, after word identification is completed, to engage in extra processing at the letter level. Alternatively, in a more recent study,

Table 4

Proportion of Detection Errors in Experiment 1 of the Study by Healy, Oliver, and McNamara (1987) as a Function of Condition, Test-Word Type, and Test-Word Spelling (Correct or Misspelled) Test-Word Type

\begin{tabular}{lccccc}
\cline { 2 - 3 } Condition & \multicolumn{2}{c}{ The } & & \multicolumn{2}{c}{ Other Words } \\
\cline { 2 - 3 } \cline { 5 - 6 } & Correct & Misspelled & & Correct & Misspelled \\
\hline One word & .02 & .01 & & .03 & .04 \\
Four word & .16 & .00 & & .06 & .03 \\
Paper & .55 & .13 & & .30 & .10 \\
\hline
\end{tabular}

Hadley and Healy (1991) suggested that with only one word in view, subjects would be forced to fixate every word in a passage. Ordinarily-that is, with normal text and several words in view - familiar words may be identified in the parafovea (i.e., while fixating a previous word) and thus left unfixated. An eye-movement monitoring experiment by O'Regan (1979), for example, showed that the word the is often identified in the parafovea and is thus not fixated while reading. Consequently, Hadley and Healy speculated that the perceptual unit that predominates in reading may depend on where identification takes place in the visual field. This parafovealprocessing hypothesis explains the large number of letterdetection errors on common words as resulting from the fact that words that are identified in the parafovea are not fixated during reading, so that letter identification is impeded. That is, the familiar visual configuration of a common word may allow for it to be identified in the parafovea before its component letters are identified, presumably because greater acuity and resolution are needed for the identification of individual letters than for the identification of a global word shape. If the same word is fixated, it is much less likely that it would be identified as a whole before its individual letters are identified.

Hadley and Healy (1991) reported four experiments which provided support for this hypothesis; I will describe only Experiment 4 here. In this experiment, we provided the subjects with a small aperture cut into an index card and used as a viewing window. The subjects moved this window across the page as they read the text. The window was large enough for either only 5 letters (e.g., the word the and the two surrounding spaces) or only 15 letters (e.g., the word the along with the immediately surrounding spaces and adjacent words or letters) to be viewed, as illustrated in Table 2 . The subjects in both window-size conditions were given the same text to read, and the text, which was a normal prose passage identical to that used earlier (Healy, 1976; see also Table 1), was printed normally. Unlike the procedure by Healy, Oliver, and McNamara (1987), in which the duration of the one-word and four-word displays was constant and fixed by the computer, in this experiment the subjects controlled the movement of the window. Since under the latter conditions there is no reason why subjects would spend extra processing time at the letter level after word identification is completed in the smallerwindow condition, this experiment allows for a direct test of the parafoveal-processing hypothesis because the manipulation of window size directly manipulates the availability of a parafoveal preview. No parafoveal preview would be possible with the 5-letter window, but a preview would be possible with the 15-letter window. The parafoveal-processing hypothesis leads to the prediction that only the 15-letter window would display a larger proportion of letter-detection errors on the word the than on other words. Indeed, as predicted, the proportion of detection errors differed across test words only for the 15-letter window (the, .15; other, .06). For the 5-letter window, the difference was not significant 
the .12 ; other, .10$)$. Thus, eliminating the availability of 1 parafoveal preview, as in the 5-letter window, elimilated the difference between letter-detection errors on the vord the and on other words. It therefore seems clear that he location of a word in the subject's visual field is a :rucial determinant of the pattern of letter-detection erors on the word. When a familiar word occurs in the arafovea, it may be identified before its component leters are identified, and therefore letter-detection errors nay result, whereas when the same word is fixated, it is nuch less likely that word identification will precede etter identification, resulting in little chance of a letterletection error. Although my original study (Healy, 1976) ruled out the location of the letter in a word as an mportant cause of letter-detection errors on the word he, this more recent study demonstrated that a revised version of the location hypothesis in terms of word losation in the visual field has much merit. Likewise, alhough my original study ruled out the pronunciation of he letter $t$ as a sufficient explanation for letter-detection zrrors on the word the, my colleagues and I have found nore recently that phonetic processes do affect letter derection in some cases.

\section{Phonetic Factors}

One persistent question in the study of reading concerns the role of phonetic processes in word identification. A widely cited source of evidence on this issue is the classic study, mentioned earlier, by Corcoran (1966), who found that, in searching for the letter $e$ in a magazine article, subjects missed more silent es than pronounced es (for similar observations, see Chen, 1976; Coltheart, Hull, \& Slater, 1975; Locke, 1978; and Mohan, 1978; but for problems with these observations or bounds on their generality, also see Drewnowski \& Healy, 1982; Krueger, 1992; and Smith \& Groat, 1979). Corcoran argued that when looking for the target, subjects scanned a phonologically recoded version of the text, not just the visual representation, and missed silent es because they were not evident in the phonological version.

Subsequently, Read (1983) found that more letterdetection errors were made on the $f$ in the word of than were made on $f \mathrm{~s}$ in other words. He attributed this effect to the unusual pronunciation of the letter $f$ in the word of. Like Corcoran (1966), Read argued that subjects miss the $f \mathrm{~s}$ in of because they scan a phonologically recoded version of the passage and look for the phoneme /f/. This argument seems reasonable because the letter $f$ usually corresponds to the phoneme /f/, with of being the only exception among common words. However, Goldman and Healy (1985) found a large proportion of letterdetection errors on $f s$ in the word of even when subjects were engaged in articulatory suppression (i.e., they spoke an irrelevant word) during the detection task (normal: of, .93 ; other, .03; suppression: of, .94; other, .10). Articulatory suppression has been shown to disrupt phonological recoding in previous studies of reading (e.g., Levy, 1978). Hence, this finding provides evidence against Read's argument. The unitization hypotheses provide another explanation for the large number of letter-detection errors on the common word of. Goldman and Healy favored this unitization explanation.

Schneider, Healy, and Gesi (1991) aimed to test these two alternative explanations-that is, Read's (1983) proposal concerning the scanning of phonologically recoded text and the unitization hypotheses favored by Goldman and Healy (1985). The goal of Experiment 1 of the study by Schneider et al. was to test the unitization explanation using a previous finding by Healy, Conboy, and Drewnowski (1987) that the tendency of subjects to make errors on a common word was greatly diminished when asterisks were inserted between all letters. The asterisks should impede the formation of processing units larger than the letter by disrupting the familiar visual configuration of the units. In Experiment 1 by Schneider et al., asterisks were introduced into a passage for one group of subjects, whereas a second group of subjects were shown the same passage printed normally. Both versions of the passage are illustrated in Table 2. Subjects in both groups were given the letterdetection task with $f$ as the target. In the normal condition, we found a large proportion of detection errors for of $(.56)$ relative to that for the other test words $(.03)$; the effect of test word was greatly diminished in the asterisk condition (of, .17; other, .02), although it did remain substantial there.

These results imply that unitization can provide at least a partial explanation of the large proportion of detection errors on the word of. However, the unitization explanation seems inconsistent with Read's (1983) observation of no difference between of and other words when the target was the letter $o$ rather than $f$. But the only passage Read used with the $o$ target was the same single sentence we employed, which contains only four os, three of them in the word of (see Table 2). The purpose of Experiment 2 by Schneider et al. (1991) was to determine whether subjects would miss a greater proportion of $o$ in the word of with a longer passage that has more instances of the target letter. One group of subjects was given $o$ and another was given $f$ as the target. The passage was written so that every test word contained both targets and there were no other instances of either target in the passage. We found a much greater proportion of errors on of (.52) than on the other test words (.05) for the $f$-target condition; this effect of test word was much smaller, but still statistically reliable, for the $o$-target condition (of, .10; other words, .02). These findings imply that unitization can account for the greater proportion of detection errors on of than on other words, but only partially. Other factors must also be contributing to the large effect with the target letter $f$.

To determine whether phonetic factors contribute to the failure of subjects to detect $f s$ in the word of, Schneider et al. (1991) used a procedure developed earlier by Schneider, Healy, Ericsson, and Bourne (1989). This procedure involves a comparison of two new detection tasks. In the auditory task, subjects listen to a passage and write down every word they hear that includes a 
given target letter. (Note that despite the auditory presentation of the material, the subjects' task is to search for an orthographic, not a phonemic, target.) In the corresponding visual task, subjects read the passage and write down every word they see that includes the target. In the earlier study, Schneider et al. (1989) found that of the two tasks, only the visual task yielded evidence for unitization - that is, more letter-detection errors on common words than on less frequent words. If the detection errors on $f$ in of are due to its unusual pronunciation, as argued by Read (1983), the $f$ in of should be missed in the auditory task as well as in the visual task. If, on the other hand, the detection errors on $f$ in of are due to unitization, the $f$ in of should be no more likely than the $f \mathrm{~s}$ in other words to be missed in the auditory task.

Schneider et al. (1991) used the detection-task comparison with the targets $f$ and $o$ in Experiment 3. With both modalities, for the target $f$ there was a larger proportion of errors on of (visual, .57; auditory, .45) than on the control word if (visual, .10; auditory, .19), even though if is also a common word and is matched with of in terms of word length and location of the target letter; the proportion of errors on of was larger, too, than that on other words with $f$ (visual, .10; auditory, .22). This finding is consistent with the hypothesis that the large proportion of errors on $f$ in of is due in part to its unusual pronunciation. For the target $o$, with the visual but not with the auditory modality, the proportion of errors on of (visual, .16; auditory, .20) was higher than that on other test words (visual, .02; auditory, .20), suggesting that unitization is largely responsible for that effect. The difference between the two modalities suggests that pronunciation of the target letter was the factor responsible for the effect of test word found with the target $f$ in the auditory modality as well as in the visual modality.

According to Read (1983), pronunciation of the target affects detection errors because subjects scan a phonologically recoded version of the text for the /f/ phoneme and they miss the $f$ in of because it is pronounced like a $/ \mathrm{v} /$ rather than an $/ \mathrm{f} /$. The aim of Experiment 4 by Schneider et al. (1991) was to test this explanation more directly. Three different conditions were compared, in one of which subjects were given the single target letter $f$, as in earlier experiments. In a second condition, subjects were given the pair of target letters $f$ and $v$. If subjects make detection errors on the $f$ in of because it is pronounced like a $v$, they should be able to detect the $f$ in this condition even if they search for phonemes instead of letters. In the third condition, subjects were given the pair of target letters $f$ and $z$. There were no $z \mathrm{~S}$ or $v \mathrm{~s}$ in the test passage. This condition thus allows for a comparison of the effects of having two targets with the effects of having a single one. We found that in all three conditions the proportion of detection errors was much higher for the test word of ( $f$ target, $.78 ; f$ or $v$ target, $.64 ; f$ or $z$ target, .70$)$ than it was for the other test words ( $f$ target, $.06 ; f$ or $v$ target, .07; $f$ or $z$ target, .09). Because subjects continued to miss $f$ s in the word of even when they were told to search for the letter $v$ as well as the letter $f$, these results provide evidence against Read's phonologicalrecoding hypothesis. It seems unlikely that subjects given the targets $f$ or $v$ would miss the $f$ in of because they are searching only for the phoneme/f/. Hence, some other phonetic processes must be responsible for the failure of subjects to detect the $f$ in of.

The findings of Experiment 3 (Schneider et al., 1991) that support the hypothesis that phonetic processes contribute to the failure of subjects to detect $f \mathrm{~s}$ in of may appear inconsistent with those of Experiment 4 that provide evidence against the phonological-recoding hypothesis put forth by Read (1983). This inconsistency can be removed, however, by acknowledging that there are two different types of phonetic processes that have been proposed previously (e.g., Besner \& Davelaar, 1982; Foss \& Blank, 1980). One type is used for accessing the lexicon, while the second type is used for short-term memory storage. Besner and Davelaar (1982) showed that only the memory processes are affected by articulatory suppression. Because articulatory suppression did not eliminate the large proportion of detection errors on $f \mathrm{~s}$ in of in the study by Goldman and Healy (1985), this effect is probably not attributable to memory processes. Instead, it is possible that lexical phonetic processes are responsible. If we assume that speech perception and reading share the relevant lexical phonetic processes, we have support for this possibility from our finding that a large proportion of detection errors occurs on $f$ in of with the auditory modality as well as with the visual modality.

How could lexical phonetic processes account for detection errors on $f$ in of? As an explanation for the large proportion of detection errors on $f$ in of, Schneider et al. (1991) proposed that detection error rate is increased whenever there is a mismatch between the phoneme and letter representations of the target in a word. That is, subjects miss the $f$ in of because there is a mismatch between the letter $f$ and the phoneme $/ \mathrm{v} /$ in the lexical entry. This explanation implies that a model of word identification needs to include both letter and phoneme levels as well as a cross-checking or communication between the two levels (see LaBerge \& Samuels, 1974, for a similar proposal). ${ }^{7}$

In subsequent experiments, Schneider et al. (1991) and Schneider and Healy (1993) provided additional support for this explanation. For example, in one experiment, Schneider and Healy (1993) used the auditory detection task with phonemes rather than letters as targets, not unlike studies of phoneme monitoring (see, e.g., Cutler, Mehler, Norris, \& Segui, 1987; Healy \& Cutting, 1976). Two conditions were compared, in one of which subjects searched for the phoneme $/ \mathrm{v} /$, while in the other they searched for the schwa phoneme/uh/. The passages used were constructed so that each test word in them included both target phonemes (e.g., of, love) and they included no other instances of either target phoneme. According to our cross-checking hypothesis, subjects should make a larger proportion of errors on of than on other test words when searching for the $/ \mathrm{v} /$ phoneme, but not when searching for the $/ \mathrm{uh} / \mathrm{phoneme}$, because there 
is a mismatch between the phoneme and letter representations of the target for the /v/ target but not for the /uh/ target. In agreement with these predictions, we found that there were significantly more detection errors on of than on other test words for the /v/ phoneme (of, .29; other words, .03) but not for the /uh/ phoneme (of, .21; other words, .14).

\section{Semantic and Syntactic Factors}

Now that I have described some recent studies showing the importance of visual and phonetic factors in letter- and word-identification processes in reading, I shall turn to a discussion of the importance of syntactic and semantic factors. Work published by Koriat, Greenberg, and Goldshmid (1991; see also Greenberg \& Koriat, 1991; Greenberg, Koriat, \& Shapiro, 1992; Koriat \& Greenberg, 1991, 1993, 1994) helped stimulate my interest in this question because they found evidence supporting the influence of syntactic factors on letter detection in Hebrew and English (see Haber \& Schindler, 1981, and Schindler, 1978, for earlier evidence also suggesting the influence of syntactic function).

Work by Koriat and Greenberg. On the basis of their finding of syntactic effects on letter detection, Koriat and Greenberg (1994) have proposed a structural account of letter detection, according to which function words play an early role in sentence processing but then recede to the background, so that their component letters may be missed in a letter-detection task. By this account, letter detection thus reflects processes occurring after word identification is completed, rather than reflecting unitization processes occurring during lexical access. However, it appears that the unitization framework can provide alternative accounts for most if not all of the findings summarized by Koriat and Greenberg.

For example, Koriat et al. (1991) conducted an experiment in which they compared two kinds of Hebrew phrases: a preposition followed by a noun, and a contraction in which the first letter of the preposition was attached to the noun as a prefix. They found more letterdetection errors for the prefix than for the preposition. That is, subjects made many letter-detection errors on the first letter of the contraction, even though the combination of first letter and noun was uncommon. In describing this study later, Koriat and Greenberg (1994) concluded that "function units are concealed because of their syntactic role-not because of their familiarity" (p. 349), thereby suggesting that they provided evidence for the structural account and against the unitization framework. However, that evidence was based on the assumption that "the frequency of the orthographic string is the critical factor for letter omissions" (p. 349), which is not an assumption included in the unitization framework. To the contrary, Drewnowski and Healy (1980) made it clear in their study of detection errors in the trigram -ing, which provided support for the unitization framework, that it may be the frequency of the morpheme affix, rather than that of the entire orthographic string, that is the critical factor for letter detection in some cases.

Similarly, in describing their study of letter detection in nonwords (Koriat \& Greenberg, 1991), Koriat and Greenberg (1994) conclude that "the missing-letter effect can be obtained even for letter strings with zero frequency of occurrence in the language" (p. 351), again suggesting that they have provided evidence against the unitization framework, in which the frequency of a unit in the language is of paramount importance. However, they showed that the nonwords demonstrating the missingletter effect either included a morpheme affix which could be viewed as the relevant unit rather than the entire nonword or were misspellings of a very frequent word (e.g., fom for for) which could be viewed as the relevant unit, as in the earlier study by Healy and Drewnowski (1983), which found the missing letter effect for some misspellings of the word the.

It is also important to note that although the structural account of Koriat and Greenberg (1994) provides a compelling explanation for the syntactic effects on letter detection, it cannot by itself account for many of the other effects obtained with the letter-detection task. For example, it cannot account for observed differences between common and rare nouns (i.e., content words; see Healy, 1976, 1980) or for many effects involving perceptual aspects of words, such as the typecase or font in which they are printed or the spacing between letters (see, e.g., Drewnowski \& Healy, 1977; Healy, Conboy, \& Drewnowski, 1987; Schneider \& Healy, 1993). Likewise, the structural account has no explanation for phonetic effects in letter detection, such as those concerning syllable stress (see, e.g., Drewnowski \& Healy, 1982; Goldman \& Healy, 1985) or the pronunciation of the target letter (see, e.g., Read, 1983; Schneider et al., 1991).

Work by Moravesik and Healy. In further pursuit of this issue, Moravcsik and Healy (in press) conducted a set of experiments that also demonstrate dramatic effects of semantic and syntactic factors on letter detection. I will summarize the first two of these experiments here.

In Experiment 1, we looked at semantic and syntactic factors by changing the meaning and grammatical function of the word the in a prose passage. The passage consisted of a story about a young man who was trying to find two spices to use in a Thai recipe. The word the was used in some cases in the passage to refer to a type of Thai spice. In an alternative version of the passage, the word thy was used in place of the to refer to the spice. A sample sentence from each version of the passage is included in Table 2. Note that the name of the spice was not in quotes or made to stand out in any other way. Each version of the passage was shown to half of the subjects.

We found that the proportion of detection errors on the word the was very high when it was used in the ordinary way (.38), but that it decreased dramatically when the meaning and grammatical function were changed. The proportion of letter-detection errors on the word the when it referred to a spice was essentially on the floor 
$(.02)$, was no different from that on the word thy when it was used in the same way $(.01)$, and was actually less than the proportion of errors on other test words (.13). These results show that semantic and syntactic factors are indeed of crucial importance, contrary to the suggestion from my initial study (Healy, 1976), which showed that scrambling the words in a passage did not affect the relative proportion of letter-detection errors on the word the. The present findings are noteworthy because they suggest that grammar and meaning play important roles very early on in letter and word processing, before letter detection is completed.

To extend the findings from the first experiment in this series, Moravcsik and Healy (in press) conducted a second experiment using a different meaning of the word the. Instead of constructing a new use for the word the, in this experiment, one of its existing, but relatively unusual, uses was employed. Specifically, the word the referred to itself - that is, to the definite article. We employed two different versions of an excerpt from a grammar textbook about the definite article. This excerpt included the phrase "the definite article" several times. One version of the passage was identical to the excerpt, and the other version was the same except that every instance of the phrase "the definite article" was replaced by the word the. One sentence from each version of the passage is included in Table 2 . It should be noted that the word the in the phrase "the definite article" is in the same place in the sentence and that the same words immediately precede it as precede the word the when it is used on its own to mean the definite article. Also note that the word the was not placed in quotes or made to stand out in any way even when it referred to itself. Each version of the passage was shown to half of the subjects.

As expected, we found that the proportion of detection errors was high for the word the when it occurred either in the phrase "the definite article" $(.37)$ or elsewhere in the passage as a function word (.39), but that the proportion of errors was much lower for the word the when it occurred as a content word referring to the definite article (.15). In fact, the proportion of errors on the word the when used in this special way was no greater than the proportion of errors on other test words (.18). Again, these results give strong support to the hypothesis that semantic and syntactic factors influence the pattern of letter-detection errors.

In the two experiments described here by Moravcsik and Healy (in press), semantic and syntactic factors were confounded; that is, both the meaning and grammatical function of the word the were changed. However, in subsequent experiments of that series, semantic factors on their own were shown to be important by holding constant the grammatical function of the words and varying only their meaning. In one case (Experiment 5), a reduction in detection error rate was found for the word the when it was used with its standard grammatical function as the definite article but in an ambiguous, or vague, noun phrase (i.e., the noun phrase could refer to either of two different items). For example, in one passage, two different presents were mentioned, followed by a reference to "the present." Syntactic factors on their own were also shown to be important in a more recent study by Moravcsik and Healy (1994), in which it was found that subjects made more correct letter detections on the word the when it belonged to the subject than they did when it belonged to the object of a sentence, even when the semantic role of the noun phrase was controlled by using active and passive versions of the same sentences. It thus appears that semantic and syntactic factors both jointly and independently affect letter detection.

\section{Conclusions}

In my original work with the letter-detection task (Healy, 1976), I found evidence supporting the important role of unitization processes and evidence against the role of letter location, letter pronunciation, and the semantic and syntactic redundancy of the words. In contrast, in my more recent work, without denigrating the importance of unitization, my collaborators and I have found that word location in the parafovea (Hadley \& Healy, 1991), the phonetic representation of the letter (Schneider \& Healy, 1993; Schneider et al., 1991), and the semantic and syntactic function of the word in the text (Moravcsik \& Healy, 1994 , in press) also play crucial roles in letter detection. Can we incorporate these additional factors into the framework provided by the unitization hypotheses? The answer to this question is clearly positive, as should be clear by reconsidering Figure 1, which shows the operation of these hypotheses for the reading of a short segment of text by a hypothetical subject. The additional factors can be incorporated by making the following three new assumptions: (1) identification at the word level is much less likely to precede identification at the letter level when the word is fixated rather than occurring in the parafovea; (2) along with the letter level, there must be a phoneme level as well as a provision for a cross-checking or communication between those two levels; and (3) word identification must require access to semantic and syntactic information, not just information about the visual configuration and component letters, phonemes, and syllables. This last assumption would, for example, allow for words with a common meaning and grammatical function to be identified before words with unusual semantic and syntactic attributes.

In summary, the simple task of circling letters in a word depends not only on the familiarity of the word's configuration but also on the location of the word in the reader's visual field, the phonetic representation of the letter in the word, and the word's meaning and grammatical function. Thus, the letter-detection task provides a window illuminating a wide range of cognitive processes involved in reading text.

\section{REFERENCES}

Allen, P. A., \& Emerson, P. L. (1991). Holism revisited: Evidence for parallel independent word-level and letter-level processors during word recognition. Journal of Experimental Psychology: Human Perception \& Performance, 17, 489-511. 
Allen, P. A., \& MAdDEN, D. J. (1990). Evidence for a parallel input serial analysis model of word processing. Journal of Experimental Psychology: Human Perception \& Performance, 16, 48-64.

BesNer, D., \& DavelaAR, E. (1982). Basic processes in reading: Two phonological codes. Canadian Journal of Psychology, 36, 701-711.

CHEN, K. (1976). Acoustic image in visual detection for deaf and hearing college students. Journal of General Psychology, 94, 243-246.

Coltheart, M., Hull, E., \& Slater, D. (1975). Sex differences in imagery and reading. Nature, 253, 438-440.

CorCoran, D. W. J. (1966). An acoustic factor in letter cancellation. Nature, 210, 658 .

Cunningham, T. F., Healy, A. F., Kanengiser, N., Chizzick, L., \& WILLITTS, R. L. (1988). Investigating the boundaries of reading units across ages and reading levels. Journal of Experimental Child Psychology, 45, 175-208.

Cutler, A., Mehler, J., Norris, D., \& Segui, J. (1987). Phoneme identification and the lexicon. Cognitive Psychology, 19, 141-177.

DREWNOWSKI, A. (1978). Detection errors on the word the: Evidence for the acquisition of reading levels. Memory \& Cognition, 6, 403. 409.

DREWNowsKI, A. (1981). Missing -ing in reading: Developmental changes in reading units. Journal of Experimental Child Psychology, 31, 154-168.

DreWNOWSKI, A., \& HeAly, A. F. (1977). Detection errors on the and and: Evidence for reading units larger than the word. Memory \& Cognition, 5, 636-647.

DREWNOWSKI, A., \& HeAly, A. F. (1980). Missing -ing in reading: Letter detection errors on word endings. Journal of Verbal Learning \& Verbal Behavior, 19, 247-262.

Drewnowski, A., \& HeALY, A. F. (1982). Phonetic factors in letter detection: A reevaluation. Memory \& Cognition, 10, 145-154

FORSTER, K. I. (1970). Visual perception of rapidly presented word sequences of varying complexity. Perception \& Psychophysics, 8 , 215-221.

Foss, D. J., \& BLANK, M. A. (1980). Identifying the speech codes. Cognitive Psychology, 12, 1-31.

Golding, W. (1959). Lord of the flies. New York: Capricorn.

Goldman, H. B., \& Healy, A. F. (1985). Detection errors in a task with articulatory suppression: Phonological recoding and reading. Memory \& Cognition, 13, 463-468.

GreenberG, S.N., \& Koriat, A. (1991). The missing-letter effect for common function words depends on their linguistic function in the phrase. Journal of Experimental Psychology: Learning, Memory, \& Cognition, 17, 1051-1061

Greenberg, S. N., Koriat, A., \& Shapiro, A. (1992). The effects of syntactic structure on letter detection in adjacent function words. Memory \& Cognition, 20, 663-670.

HABER, R. N., \& SCHINDLER, R. M. (1981), Error in proofreading: Evidence of syntactic control of letter processing? Journal of Experimental Psychology: Human Perception \& Performance, 7, 573-579.

HADLEY, J. A., \& HEALY, A. F. (1991). When are reading units larger than the letter? A refinement of the unitization reading model. Journal of Experimental Psychology: Learning, Memory, \& Cognition, 17, 1062-1073.

HEALY, A. F. (1976). Detection errors on the word the: Evidence for reading units larger than letters. Joumal of Experimental Psychology: Human Perception \& Performance, 2, 235-242.

Healy, A. F. (1980). Proofreading errors on the word the: New evidence on reading units. Journal of Experimental Psychology: Human Perception \& Performance, 6, 45-57.

Healy, A. F. (1981a). Cognitive processes in reading text. Cognition, 10, 119-126.

HEALY, A. F. (1981b). The effects of visual similarity on proofreading for misspellings. Memory \& Cognition, 9, 453-460.

Healy, A. F., Conboy, G. L., \& Drewnowski, A. (1987). Characterizing the processing units of reading: Effects of intra- and interword spaces in a letter detection task. In B. K. Britton \& S. M. Glynn (Eds.), Executive control processes in reading (pp. 279-296). Hillsdale, NJ: Erlbaum.

Healy, A. F., \& Cunningham, T. F. (1992). A developmental evaluation of the role of word shape in word recognition. Memory \& Cognition, 20, 141-150.
Healy, A. F., \& Cutting, J. E. (1976). Units of speech perception: Phoneme and syllable. Journal of Verbal Learning \& Verbal Behavior, 15, 73-83.

HeALY, A. F., \& DREwnowsKI, A. (1983). Investigating the boundaries of reading units: Letter detection in misspelled words. Journal of Experimental Psychology: Human Perception \& Performance, 9, 413-426.

Healy, A. F., Fendrich, D. W., \& Proctor, J. D. (1990). Acquisition and retention of a letter-detection skill. Journal of Experimental Psychology: Learning, Memory, \& Cognition, 16, 270-281.

Healy, A. F., Oliver, W. L., \& McNamara, T. P. (1987). Detecting letters in continuous text: Effects of display size. Journal of Experimental Psychology: Human Perception \& Performance, 13, 279290.

Healy, A. F., Volbrecht, V. J., \& Nye, T. R. (1983). The effects of perceptual condition on proofreading for misspellings. Memory \& Cognition, 11, 528-538.

Johnson, N. F., Allen, P. A., \& Strand, T. L. (1989). On the role of word frequency in the detection of component letters. Memory \& Cognition, 17, 474-482

KANWISHER, N. G. (1987). Repetition blindness: Type recognition without token individuation. Cognition, 27, 117-143.

KLEIN, G. S. (1964). Semantic power measured through the interference of words with color-naming. American Journal of Psychology, 77, 576-588

Koriat, A., \& GREENBERG, S. N. (1991). Syntactic control of letter detection: Evidence from English and Hebrew nonwords. Journal of Experimental Psychology: Learning, Memory, \& Cognition, 17, 1035-1050.

Koriat, A., \& Greenberg, S. N. (1993). Prominence of leading functors in function morpheme sequences as evidenced by letter detection. Journal of Experimental Psychology: Learning, Memory, \& Cognition, 19, 34-50.

Koriat, A., \& GreEnBeRg, S. N. (1994). The extraction of phrase structure during reading: Evidence from letter detection errors. $P s y$ chonomic Bulletin \& Review, 1, 345-356.

Koriat, A., Greenberg, S. N., \& GoldShMid, Y. (1991). The missingletter effect in Hebrew: Word frequency or word function? Journal of Experimental Psychology: Learning, Memory, \& Cognition, 17, 66-80.

KRUEGer, L. E. (1970). Search time in a redundant visual display. Journal of Experimental Psychology, 83, 391-399.

KRUEGER, L. E. (1982). A word-superiority effect with print and braille characters. Perception \& Psychophysics, 31, 345-352.

KrUEGER, L. E. (1989). Detection of intraword and interword letter repetition: A test of the word unitization hypothesis. Memory \& Cognition, 17, 48-57.

KRUEGER, L. E. (1992). The word-superiority effect and phonological recoding. Memory \& Cognition, 20, 685-694.

KRUEGER, L. E., \& Weiss, M. E. (1976). Letter search through words and nonwords: The effect of fixed, absent, or mutilated targets. Memory \& Cognition, 4, 200-206.

LaBerge, D., \& SAMUels, S. J. (1974). Toward a theory of automatic information processing in reading. Cognitive Psychology, 6, 293-323.

LEvy, B. A. (1978). Speech processes during reading. In A. M. Lesgold, J. W. Pellegrino, S. D. Fokkema, \& R. Glaser (Eds.), Cognitive psychology and instruction. New York: Plenum.

LOCKE, J. L. (1978). Phonemic effects in the silent reading of hearing and deaf children. Cognition, 6, 175-187.

MACLEOD, C. M. (1991). Half a century of research on the Stroop effect: An integrative review. Psychological Bulletin, 109, 163-203.

MCClelland, J. L., \& Rumelhart, D. E. (1981). An interactive activation model of context effects in letter perception: Part I. An account of basic findings. Psychological Review, 88, 375-407.

Mohan, P. J. (1978). Acoustic factors in letter cancellation: Developmental considerations. Developmental Psychology, 14, 117-118

Moravcsik, J. E., \& Healy, A. F. (1994, April). Does syntactic role affect letter detection? Paper presented at the annual meeting of the Rocky Mountain Psychological Association, Las Vegas, NV.

MoRavCSIK, J. E., \& Healy, A. F. (in press). The effect of meaning on letter detection. Journal of Experimental Psychology: Learning, Memory, \& Cognition. 
O'REGAN, K. (1979). Saccade size control in reading: Evidence for the linguistic control hypothesis. Perception \& Psychophvsics, 25, 501509

Peterzell, D. H., Sinclair, G. P., Healy, A. F., \& Bourne, L. E., Jr. (1990). Identification of letters in the predesignated target paradigm: A word superiority effect for the common word the. American Journal of Psychology, 103, 299-315.

Proctor, J. D., \& HeALY, A. F. (1985). A secondary-task analysis of a word familiarity effect. Journal of Experimental Psychology: Human Perception \& Performance, 11, 286-303.

Proctor, J. D., \& Healy, A. F. (in press). Acquisition and retention of skilled letter detection. In A. F. Healy \& L. E. Bourne, Jr. (Eds.), Learning and memory of knowledge and skills: Durability and specificity (pp. 282-299). Thousand Oaks, CA: Sage.

Proctor, J. D., \& Healy, A. F., \& Fendrich, D. W. (1988, March). The disappearance of the word inferiority effect: Strategy shift or perceptual effect? Paper presented at the annual meeting of the Southeastern Psychological Association, New Orleans, LA.

RAYNER, K., \& POLLATSEK, A. (1989). The psychology of reading. Englewood Cliffs, NJ: Prentice-Hall.

READ, J. D. (1983). Detection of Fs in a single statement: The role of phonetic recoding. Memory \& Cognition, 11, 390-399.

ReICHER, G. M. (1969). Perceptual recognition as a function of meaningfulness of stimulus material. Journal of Experimental Psychology, 81, 275-280.

Rumelhart, D. E., \& MCClelland, J. L. (1982). An interactiveactivation model of context effects in letter perception: Part 2 . The contextual enhancement effect and some tests and extensions of the model. Psychological Review, 89, 60-94.

SCHINDLER, R. M. (1978). The effect of prose context on visual search for letters. Memory \& Cognition, 6, 124-130.

SCHNEIDER, V. I., \& HeALY, A. F. (1993). Detecting phonemes and letters in text: Interactions between different types and levels of processes. Memory \& Cognition, 21, 739-751.

Schneider, V. I., Healy, A. F., Ericsson, K. A., \& Bourne, L. E., JR. (1989). Letter detection errors in reading, auditory, and memory tasks. Journal of Memory \& Language, 28, 400-41 1.

SChNeider, V. I., Healy, A. F., \& GeSI, A. T. (1991). The role of phonetic processes in letter detection: A reevaluation. Journal of Memory \& Language, 30, 294-318.

SMith, P. T., \& GROAT, A. (1979). Spelling patterns, letter cancellation and the processing of text. In P. A. Kolers, M. E. Wrolstad, \& H. Bouma (Eds.), Processing of visible language (Vol. 1, pp. 309-324). New York: Plenum.

STROOP, J. R. (1935). Studies of interference in serial verbal reactions. Journal of Experimental Psychology, 18, 643-662.

WhEELER, D. D. (1970). Processes in word recognition. Cognitive Psychology, 1, 59-85.

\section{NOTES}

1. It is important to distinguish between the overall, or macrolevel, speed-accuracy trade-off considered here for a passage as a whole and a microlevel speed-accuracy trade-off, which would apply to the individual words in a passage. Given a macrolevel speed-accuracy trade-off, subjects would make more letter-detection errors on passages that they process more quickly. In contrast, given a microlevel speed-accuracy trade-off, subjects would make more letter-detection errors on words that they process more quickly. Note that the procedures used in Healy (1976) did not allow the determination of the degree to which a microlevel speed-accuracy trade-off (which was necessarily embedded in the macrolevel speed-accuracy trade-off) was contributing to the macrolevel speed-accuracy trade-off. However, a microlevel speed-accuracy trade-off is the basis for a processing-time hypothesis proposed recently by Moravcsik and Healy (in press), according to which the length of time spent processing a given word is a major determinant of the proportion of letter-detection errors made on that word.

2. Most previous studies of the word-superiority effect and wordfrequency advantage with the masking paradigm avoided common function words. However, in a study with the masking paradigm by Peterzell, Sinclair, Healy, and Bourne (1990), a word-superiority effect was found for the common function word the even under circumstances in which the effect was not found for less common words.

3. Note that research with the Stroop (1935) task also shows poorer performance (i.e., greater interference) with words than with nonwords and with common words than with rare words (see, e.g., Klein, 1964; MacLeod, 1991).

4. For comparisons of these unitization hypotheses with related models emphasizing holistic processing and for tests of unitization using paradigms other than the letter-detection task-some of which showed word superiority rather than word inferiority-see, for example, Allen and Emerson (1991), Allen and Madden (1990), Johnson, Allen, and Strand (1989), and Krueger (1989).

5 . The same general pattern of results was evident for correct response latencies as was evident for errors, which speaks against potential problems not only concerning speed-accuracy trade-offs (see Note 1) but also concerning floor effects on error rate. It is particularly interesting to note that whereas response latencies in the oneword condition were fastest on the word the when it was spelled correctly, response latencies in the four-word condition were slowest in that situation (see Healy, Oliver, \& McNamara, 1987, pp. 282-283).

6. As mentioned earlier, work by Krueger and his colleagues (Krueger, 1970, 1982; Krueger \& Weiss, 1976) obtained word superiority, not inferiority, with multi-item displays. However, there are many differences between the procedures used by Krueger and his colleagues and those used in the letter-detection task (see Healy, 1976, 1980 for discussions of some procedural differences). Krueger and his colleagues used a search task in which subjects looked for target letters in lists containing either words or nonwords, responding "yes" whenever they found a target and "no" if no target was found in a list. One critical difference between Krueger's procedures and those used in the letter-detection task concerns the fact that detection was stressed in Krueger's search task whereas reading, rather than detection, was stressed in the letter-detection task (see Healy, 1976 for a discussion of this difference). Further, the words in the letter-detection task are typically presented in a paragraph format, whereas those in Krueger's search task were typically presented in a list format. In fact, Drewnowski and Healy (1977) found that the word-frequency disadvantage was eliminated in the letter-detection task when the words were presented in a list, rather than a paragraph, format.

7. Note that the cross-checking postulated by Schneider et al. (1991) is also similar to a proposal by Krueger (1992) to account for his finding of an enhanced word-superiority effect for silent letters in words. However, whereas Schneider et al. proposed that a mismatch between the phoneme and the letter representations of the target would disturb performance on the letter-detection task, Krueger (1992) proposed that such a mismatch would facilitate performance on his task in which single words rather than prose were presented, and in which a "yes" or "no" response was required to each word.

(Manuscript received December 23, 1993; revision accepted for publication May 8, 1994.) 